\title{
DIÁlOGO SOBRE O ENSINO DE FILOSOFIA NO ENSINO MÉDIO
}

\author{
José Humberto Ferreira ${ }^{1}$
}

Resumo: A Tradição filosófica testemunha a relevância do diálogo no movimento do pensamento filosófico. De um lado, é necessária à escuta da produção filosófica na história da filosofia e, do outro lado, para avançar na produção da criação de novos conceitos filosóficos. O presente artigo tem como principal objeto fomentar uma discussão acerca da importância do ensino de filosofia para estudantes no ensino médio. Os principais autores utilizados que ressaltam a importância do ensino de filosofia para estudantes do Ensino Médio são: Ortega y Gasset (1883-1955) e Sílvio Gallo (nascido em 1963). Para Ortega y Gasset, o ensino de filosofia consiste mesmo em tomar a atividade filosófica mesma, o filosofar mesmo, e submetê-lo radicalmente a uma análise filosófica (1971) com o método em círculos concêntricos. Para Sílvio Gallo, a filosofia é a experiência essencialmente do pensamento, que nos permite equacionar um problema; e a aula de filosofia deverá oportunizar ao estudante a experiência da produção do pensamento conceitual.

Palavras-chave: Diálogo. Filosofia. Ensino. Conceito.

\section{INTRODUÇÃO}

O Ensino da filosofia pode assumir muitas formas na sua prática pedagógica de ensinoaprendizagem. Pode assumir a forma de monólogo por parte do professor explicador e ouvinte de estudante. Poderá também assumir a forma de um diálogo filosófico em que ocorra a interação entre aquele que ensina e aquele que aprende. Tal prática tem sido a preferência da maioria dos docentes. Embora a forma dialógica seja a preferida, ela pode ser transformada em monólogo, alertam Deleuze e Guattari (2010) que não são favoráveis ao ensino da filosofia como forma de debate, de discussão, como se apenas o debate configurasse o conhecimento de filosofia. O que configura é a criação de conceitos. É nesta perspectiva filosófica que nos concentraremos.

\footnotetext{
${ }^{1}$ E-mail: pejhf1@gmail.com, Mestre em Filosofia e Especialista em Psicopedagogia Universidade de Pernambuco, Campus Petrolina.
} 
Popper (1980, p. 95), citado por Barbosa (2008, p. 31) posiciona-se com ideia semelhante ao dizer: "Qualquer tentativa honesta e dedicada de resolver um problema [...] filosófico, mesmo que não tenha bons resultados, parece-me mais importante do que um debate sobre problema como a natureza [...] da filosofia".

Percebemos que o discurso teórico defende a importância do ensino de filosofia em curso de Ensino Médio, como elemento favorável à formação integral da pessoa habilitando-a com os seus conteúdos, a uma leitura crítica da história e do mundo. Valoriza também uma preocupação com os direitos dos cidadãos. Entretanto, tal preocupação acenada pela sociedade civil nos seus vários âmbitos é meta a ser alcançada. É preciso perseverar no ensino de filosofia (Gallo, 2014).

Na obra "Metodologia do ensino de filosofia", Gallo (2014, p. 17) "O problema consiste no fato de que os filósofos dão pouca ou nenhuma importância à questão do ensino". A nossa intenção é fomentar a importância sobre o ensino de filosofia no ensino médio.

A obrigatoriedade da Filosofia no Ensino Médio busca fomentar discussões necessárias, tendo em vista aprofundar a natureza da mesma. A partir das considerações supracitadas, os questionamentos que deram embasamento a nossa pesquisa foram os seguintes: Para quê queremos o ensino da disciplina de Filosofia no Ensino Médio? É possível ensinar Filosofia ou ensinar a filosofar? Como essa disciplina deve ser ensinada? Como tem sido a formação dos professores de Filosofia? O tempo ofertado para as discussões filosóficas é suficiente para uma reflexão que seja de fato produtiva? Há materiais didáticos para esta finalidade? Esse material é suficiente para a demanda de discussões que devemos promover em sala de aula? Como o professor pode lidar com as reflexões necessárias em sala de aula e com os conteúdos uniformes para vestibulares? As respostas a tais questionamentos remontam a épocas passadas, nas quais diferentes abordagens eram adotadas por professores no ensino deste conteúdo e de seus pensadores, sobre o ofício de ensinar (GONÇALVES e SILVA, 2011). São todas questões relevantes. No entanto, não pretendo neste curto espaço, aprofundar todas essas; mas farei acenos necessários.

Esse estudo é considerado relevante visto que poderá contribuir para que o professor possa ter um direcionamento didático-pedagógico no modo como ministra a disciplina de filosofia no Ensino Médio, oportunizando o diálogo filosófico com dois pensadores que serão nossos guias: Gasset (1971), cujo ponto de partida para análise filosófica é a partir da categoria da vida como princípio fundamental de sua filosofia em círculos concêntricos. E Gallo (2014), o qual retrata a descrição metodológica no ensino de filosofia, uma pedagogia do conceito $^{2}$ como

${ }^{2}$ Em O que é a Filosofia? Deleuze e Guattari no capitulo (p. 23-73) defendem que apenas a filosofia produz conceitos. $\mathrm{Na}$ compreensão desses autores o conceito tem uma história, diz o acontecimento, não a essência ou a coisa, são 
caminho para ministrar a aula de filosofia no ensino médio. A partir do acima exposto, o presente artigo tem como principal objeto fomentar uma discussão sobre a importância do ensino de filosofia para estudantes do Ensino Médio.

\subsection{DISCUSSÃO TEÓRICA SOBRE O ENSINO DE FILOSOFIA}

De acordo com Aspis (2004) o ensino de filosofia foi desafio no percurso da história, tanto para quem ensinava quanto para quem aprendia. Entretanto, o desafio é maior para o ensino médio, pois não se cultivou bem uma tradição do pensar uma produção filosófica do conceito. A filosofia e o curso de filosofia foram exilados dos currículos escolares, e, ainda hoje, discute-se a possibilidade de sua exclusão. Cada pensador incorporou uma perspectiva filosófica, com a produção de conceitos novos ou incorporados do passado com novas nuanças. Conceitos sobre o homem, sobre o universo, sobre a sociedade e tantos outros. Aspis (2004) justifica que o ensino de filosofia, na medida em que visa culminar com a criação de conceitos que deem conta de seus problemas. Para Aspis (2004) não há distinção entre "ensinar filosofia" e "fillosofar". Por isso, o professor para realizar o seu ofício de ensinar deve questionar-se sobre o sentido da filosofia na escola, o seu conteúdo e a perspectiva da filosofia.

Sendo assim, Aspis (2004) ressalta que, caso proceda assim, é possível estimular no aluno o hábito de pensar para produzir filosofia e não apenas transmitir conteúdos. Tal postura é importante, visto que o professor de filosofia deve ser filósofo, como o professor de medicina deve ser médico. O ensino da disciplina de filosofia, no entendimento de cada, um leva à criação de parâmetros filosóficos para o jovem criticara história e suas circunstancias de forma original e autônoma.

Ao falar sobre o ensino de filosofia, Aspis (2004) ainda concentra-se na clássica questão que reporta a Kant (1983), cuja tese, por ele defendida, era que não se podia ensinar filosofia, mas sim a filosofar. Para Kant (1983) não é possível separar o filosofar da filosofia, já que o proposto exercício da razão deve ser feito sobre as críticas aos sistemas filosóficos. Aspis (2004),ao citar o professor Obiols (2002) que faz analise da proposição kantiana "não se pode ensinar filosofia, mas a filosofar", e isso só pode ser feito, estabelecendo um diálogo crítico com a filosofia. Hegel (1983) defende a tese em outra perspectiva ao afirmar que, quando se conhece o conteúdo da

criadas a partir de problemas vividos, colocados sobre um plano de imanência. Toda criação é singular. São estas ideias que influenciou a opção filosófica no Ensino Médio de Sílvio Gallo. 
filosofia, não apenas se está aprendendo a filosofar, mas que já se está filosofando. Assim, tanto o conteúdo como também a forma compõem o processo da atividade de produção da filosofia.

Gallo e Kohan (2000, p. 11) posicionam-se de forma dialética ao dizer: "A própria prática da filosofia leva consigo o seu produto e não é possível fazer filosofia sem filosofar, nem filosofar sem fazer filosofia". No entanto, é preciso uma atitude de não apenas ler a história da filosofia, mas repensar o seu conceito. Portanto, o ensino de filosofia requer jovens que vivam a problemática filosófica, que busquem equacionar a solução na criação de conceitos. Desse modo é significativa a afirmação de Aspis (2004), ao dizer que as aulas de filosofia são o ambiente da experiência filosófica, as quais devem oferecer elementos teóricos para uma leitura crítica sistemática, radical e transformadora da realidade. E faz tal leitura "por meio da prática do questionamento filosófico e da construção de conceitos, por meio do exercício da criatividade e avaliação filosóficas” (APIS, 2004, 81).

Sobre essa perspectiva Gasset (1971) apresenta que o professor de filosofia, dentro do que entendemos, vai ensinar a pensar filosoficamente, a organizar perguntas em torno de um problema filosófico, ler e escrever filosoficamente, a investigar e dialogar filosoficamente, avaliar filosoficamente, criar saídas filosóficas para o problema investigado. Mas, o que significa pensar filosoficamente? Conforme explicado por Gasset (1971), significa o conhecimento universal de tudo que há no universo. Para Gasset(1971, p. 61), o filósofo diferente do cientista interessa-se com a "totalidade de quanto há e, consequentemente, de cada coisa, o que ela é e junto às demais, seu lugar, seu papel e posição no conjunto de todas as coisas" .

Barbosa (2008) diz que o enfoque do ensino da filosofia deve ter como objetivo instrumentalizar teórica e praticamente os estudantes para o saber operacionalizar os conteúdos aprendidos na realidade.

É essencial a escolha do estilo filosófico. Gallo (2014, p. 39). "Ora, se são múltiplas as filosofias, se são variados os estilos do filosofar, múltiplas e variadas são também as perspectivas do ensinar a filosofia e o filosofar". Não importa o enfoque a partir da história da filosofia ou temas filosóficos. Importa, sim, é uma atitude filosófica no processo do ensino e do aprender.

De acordo com Savater (2001) citado por Gallo (2014), quatro coisas são essenciais para quem ensina filosofia: a primeira, ter ciência de que não existem estilos de filosofia; a segunda, o estudo da filosofia é importante porque a temática abordada é universal; a terceira, que nesta arte de filosofar há acertos e avanços, ninguém disse tudo, ninguém pensou tudo e, por fim, aprender a perguntar bem, para pensar, é o que move o saber filosófico.

Neste contexto, percebemos que ensinamos, mas não sabemos se o estudante aprendeu e, por isso, devemos duvidar, pois a avaliação do ensino-aprendizagem é processual. Exige tempo, 
como a semente para germinar e dar fruto. É importante duvidar se aprendemos e ensinamos. Ao falar sobre a importância da dúvida no ensino filosófico, Deleuze (2010) citado por Gallo (2014), menciona que nunca se sabe de antemão como alguém vai aprender, que amores tornam alguém bom em Latim, por meio de que encontro alguém se torna filosofo. Sem desconsiderar os recursos didáticos, a metodologia filosófica, o objetivo claro, a justificativa do ensino da disciplina, mas ter em conta que o aprender extrapola a sala de aula, não se limita ao ambiente escolar. Gallo (2014, p. 47) destaca que "aprender é tão somente o intermediário entre "nãosaber" e "saber", a passagem de um para o outro. Pode-se dizer que aprender, afinal, de contas, é uma tarefa infinita".

Para aprender filosofia é preciso colocar em dúvida o que já se sabe. É preciso ser um “mestre ignorante". No entanto, para a sua realização se faz necessário considerar o outro como protagonista de sua aprendizagem. Faz-se necessário que o mestre não seja um mero explicador, nem transmissor de conteúdos, mas aberto à pedagogia do conceito (DELEUZE, 2010). No livro O que é a Filosofia?, Gallo (2014, p. 50) apresenta o conceito em três idades, a enciclopédia que é o conjunto de conceitos e ideias, sem se preocupar com o uso, a formação profissional comercial, que remete a um uso e, por fim, a pedagogia centrada no aprendizado do conceito e em sua operatividade como experiência do pensamento.

Todavia, é costume ouvir-se dos estudantes, que filosofia é conhecimento complexo, é inútil significado existencial, sobretudo, em tempos hipermodernos. "Nasce toda uma cultura hedonista e psicologista que incita à satisfação imediata das necessidades, estimula a urgência dos prazeres, enaltece o florescimento pessoal” (LIDOVETSKY, 2004 citado por GALLO, 2014, p.22-23). Gasset (1971, p.14), ao apresentar um diálogo com a história da filosofia na obra o que é filosofia? recomenda "tomar a filosofia, o próprio filosofar e submetê-lo desde suas bases a uma análise". Nesta análise, Gasset (1971) destaca que o filosofar do professor com os alunos deverá valorizar o sentido da existência como dado fundamental.

Gasset (1971) ao apresenta a análise filosófica com quatro grandes giros contemplando a história da filosofia. No primeiro giro, constatou a impossibilidade da disciplina chegar a verdades universais, pois o conhecimento da verdade filosófica é aberto. Uma verdade filosófica é reconstruída e completada por outra. No segundo giro filosófico, é realizado um diálogo com os tipos de conhecimentos, ressaltando-seque filosofia é um saber radical, sem pressupostos e, embora a filosofia não trate do que é imediato ou útil, é necessária, pois fundamenta outros conhecimentos. $\mathrm{Na}$ terceira volta filosófica, são analisados os erros dos pensadores, dialogando com os dois sistemas dominantes, o idealismo e o realismo, com fortes críticas ao idealismo. $\mathrm{O}$ quarto giro filosófica representada pelo desafio de pensar a subjetividade idealista na 
circunstância. (GASSET, 1971)“Dou-me conta de mim no mundo, de mim e do mundo - isto é, portanto, viver" (GASSET, 1971, p.180).

\subsubsection{A FILOSOFIA COMO CRIAÇÃO DE CONCEITOS}

Este tópico visa descrever, em linhas gerais, a compreensão do ensino filosófico no ensino médio, na perspectiva de Gallo (2014) que, por sua vez, segue a orientação dos pensadores Deleuze e Guattari (2010) descrito na obra "O que é a filosofia?”.

De acordo com Deleuze (2010, p. 143) citado por Gallo (2014, p. 57), o conceito nasce de um problema ${ }^{3}$, este não é dado de antemão, mas vive-se. Desse modo, para Gallo (2014) a aula de filosofia "não é sala de museu (...) mas um local de trabalho onde os conceitos sejam ferramentas manipuláveis, como uns laboratórios onde se façam experiências e experimentações com os conceitos”.

Um pensador não é virgem no seu pensamento, recebe influência de outro. Os referidos autores criticam as atitudes da filosofia nas suas perspectivas de contemplação, de reflexão e de comunicação. ${ }^{4}$ "A filosofia consiste sempre em inventar conceitos. Ninguém pode fazer isso no lugar dela” (DELEUZE e GUATTARI,1992, p.170 citado por GALLO, 2014, p. 59). O conceito é uma forma de exprimir o mundo, o acontecimento. ${ }^{5}$ Ele nasce de uma problemática colocada sob um plano de imanência. ${ }^{6}$

\subsubsection{QUATRO PASSOS DIDÁTICOS PARA A OPERACIONALIZAÇÃO DO ENSINO DEFILOSFIA}

${ }^{3}$ Há no mundo alguma coisa que força a pensar. Este algo é objeto de um encontro fundamental e não de uma recognição. Aquilo que só pode ser sentido (o sentiendum ou o ser do sensível) sensibiliza a alma, torna-a "perplexa", isto é, força-a a colocar um problema, como se o objeto do encontro, o signo, fosse portador de problema - como se ele suscitasse problema, (Deleuze 2006a, pp.203-204 apud Gallo, 2014, pp.71)

${ }^{4}$ A filosofia não contempla, não reflete, não comunica, se bem que ela tenha de criar conceitos para estas ações e ou paixões. (Deleuze e Guattari , p. 13, 1910).

${ }^{5} \mathrm{~A}$ noção de acontecimento deleuziano se distingue da heideggeriano. Deleuze, profundamente influenciado por Bergson acredita que o acontecimento é um fenômeno da evolução criadora. "O acontecimento sustenta-se em dois níveis no pensamento de Deleuze: condição sob a qual o pensamento pensa (encontro com um fora que força a pensar, corte do caos por um plano de imanência), objetidades especiais do pensamento (o plano é povoado apenas por acontecimentos ou devires, cada conceito é a construção de um acontecimento sobre o plano). A fenomenologia "fracassa" ao pensar a heterogeneidade fundamentalmente em jogo no devir(em termos deleuzianos estritos: este não é seu problema, ela coloca um outro problema)" (FRANÇOIS, 2004,p. 11). Ortega y Gasset, no artigo "Nem vitalismo nem racionalismo", publicado em 1924 na Revista de Occidente refere-se ao vitalismo de H. Bergson, o papel da razão no conhecimento, privilegiando a intuição que se produz na vivência interna das coisas, verdadeira fonte de conhecimento. O raciovitalismo consiste basicamente na tentativa de conjugar a vida com a razão, assim toda a vida se faz acontecimento com o conjunto das circunstâncias que a compõem. A vida é conjunto de vivências.

${ }^{6}$ Não confundir o Plano de Imanência com os conceitos. O conceito é o começo da filosofia, mas o Plano é a sua instauração ( cf. Deleuze e Guattari, p. 45-73). 
O presente tópico deseja referenciar o como ensinar filosofia no ensino médio a partir sempre da perspectiva de Gallo (2014). Ele aborda duas possibilidades didáticas, uma partindo da problematização filosófica para a produção de conceito e outra partindo dos textos filosóficos na identificação de seus conceitos ao fazer o exercício de buscar o problema que levou o filosofo a produzir o conceito. A escolha depende das circunstâncias do corpo docente e discente. Todavia, não se pode seguir tal método com uma atitude dogmática, nem com a certeza matemática, mas com uma possibilidade que favoreça a atividade filosófica.

O desejo de chegar à verdade do conhecimento mediante o método, foi acentuado na época moderna por Descartes no século XVII. o método fenomenológico de Husserl marca novo enfoque Ascendem as ciências, cada uma com o seu objeto formal. A pedagogia ascende, com Comenius, com um projeto universal de ensinar tudo a todos. Diante desta floresta de caminhos de saberes, de pedagogias surgem vozes que ecoam com significativas críticas, como a do filósofo Jacques Ranciére (2002) que endossa o que Deleuze (2010) em 1960 dissera, acerca da aprendizagem ultrapassada e programada, que não se conhece por natureza, mas por provocação. Para Ranciére (2002) aprender por signos exige uma compreensão anterior para que haja uma correta interpretação. Aprende-se na relação e, conforme apresentado por Deleuze e Guatarri (2003, p.21) citado por Gallo (2014, p.87), "nunca se aprende fazendo como alguém, mas fazendo com alguém, que não tem relação com o que se aprende”.

O aprender é da ordem, não do programado, mas do acontecimento, visto que, para Gallo (2014, p. 88) “o aprendiz pensa, produz, aprende, para além e apesar de todos os métodos". A ideia do pensador é fixa: esse aprendizado por acontecimento acontece movido por problemas sentidos. É necessário o envolvimento ativo. O professor tem a sua função de mediação no processo da aprendizagem.

Todavia, é necessário abertura do mestre que faz a experiência de fazer com o estudante, e abertura do estudante que faz a experiência da aprender com metodologia, não rígida, mas como instrumento, como meio de levar a pensar filosoficamente. Também, com o propósito de contribuir para o diálogo sobre o ensino de filosofia, bem como a sua operacionalização. Falar, usando a expressão de Gallo (2014), é falar de coordenadas que abrem o caminho provocado por signos, mas caminho que permanece sempre aberto, pois a filosofia não se fecha num estilo, mas é feita de estilos diferentes.

Gallo (2014) ainda admite que a filosofia não possa ser ensinada com um método rígido, não pode ser informação do passado, mas provocação para o exercício do pensamento 
conceitual. O problema é a alma do ensino filosófico. ${ }^{7}$ Gallo (2014), com eco em Deleuze e Guattari (2010), faz restrições ao uso do método, visto que "o método é um instrumento de controle, de regulação do que se sabe e de como se sabe, de definir aquilo que é possível que cada um saiba" (GALLO, 2014, p. 88).

Portanto, cabe ao professor não ser apenas um transmissor de conteúdos, nem um explicador para ouvintes passivos, mas sim ocupar o lugar de agente de provocação filosófica. Além disso, docente e discente no ambiente de sala de aula e extra sala, devem acolher em si o sentimento inerente à tradição de quem faz filosofia, o sentimento autêntico de ignorância com autenticidade. Entretanto, tal caminho só é possível, quando se trabalha a partir de uma problemática que envolva o sentido da existência da pessoa. O professor deve selecionar problemas filosóficos, de preferência que tenham uma significação existencial para os alunos, pois filosofamos quando nos sentimos envolvidos nos problemas que serão discutidos e analisados (GALLO, 2014).

O leitor pode pensar: "na teoria tudo é fácil, mas na prática a realidade é difícil". Entretanto, o trabalho de militância permanente é necessário. Não se pode aceitar ideologia que minimize o papel verdadeiro do ensino da filosofia. Gasset (1983) parte do viver para filosofar, o seu pensamento acerca da pedagogia endossa o filosofar como análise radical.

Gallo (2014), em suas experiências filosóficas, nos descreve, nos seus quatro passos intercalados. Os passos da etapa para operacionalizar o ensino da filosofia não se separam.

A primeira das quatro etapas, para a aula de filosofia, é a "sensibilização", a qual consiste em chamar a atenção do estudante para o tema de trabalho. É o momento do despertar, considerando todo o universo cultural da realidade dos jovens. Há muitos meios de chamar atenção dos jovens, através de filme, de uma fotografia, de uma música, de uma poesia. "O vigor intelectual de um homem, como de uma ciência, se mede pela dose de cepticismo, de duvida que é capaz de digerir, de assimilar" (GASSET, 1971, p. 40).

O segundo passo didático da aula de filosofia é a "problematização". Trata-se de transformar o tema em problema experimentado. E um problema tem várias perspectivas. "Nesta etapa, estimulamos o sentido crítico e problematizador da filosofia, exercitamos o seu caráter de perguntas" (GALLO, 2014, p. 97). Um exemplo: podemos problematizar o tema da desigualdade social em vários enfoques: perguntando pela origem, como fez Rousseau. Perguntando a partir do enfoque político, como o fez Marx.

\footnotetext{
${ }^{7}$ Silvio Gallo (1914 p. 69) diz em Metodologia do ensino de filosofia, uma didática para o ensino médio, cap. 3, que o problemaé o motor do pensamento. Sem ele não há verdadeiro ensino ativo de filosofia. "Todo conceito remete a um problema..." (Deleuze e Guattari, 1910, p. 24).
} 
O terceiro passo didático na aula de filosofia é o da "investigação". Trata-se de buscar elementos que permitam a solução do problema. É o momento do diálogo com os pensadores da história da filosofia. A matéria-prima da aula de filosofia são os conceitos da história da filosofia, recurso para pensar o nosso tempo e a nossa história.

Por fim, a produção de "conceitos". "Trata-se de recriar os conceitos encontrados de modo que equacionem nosso problema, ou mesmo de criar novos conceitos” (GALLO, 2014, p. 97). Tratar a aula como uma oficina de conceitos é esperar que se criem ideias novas, é fazer com que o aluno pense por si, que crie, que invente.

\section{CONSIDERAÇÕES FINAIS}

Com a realização deste estudo, percebemos que dialogar sobre o ensino de filosofia no Ensino Médio é fundamental, pois a aula de filosofia tem como meta formar a pessoa com atitude filosófica. Constatamos, pois, que a história da filosofia é história dos conceitos acerca do conhecimento do homem, do mundo e de Deus. Mas em cada etapa da história da filosofia, com seus respectivos pensadores, foram-se tecendo conceitos diferentes de filosofia, porque diferente foi o filosofar e o contexto do pensador e a problemática vivida. A aula de filosofia e o curso de filosofia não se caracterizam apenas pela provocação ao diálogo em si, ao debate crítico, porque estes elementos são comuns aos outros saberes, mas pela produção ou ressignificação dos conceitos filosóficos. O filosofar para Gasset (1971) é análise critica radical para surgir o novo conceito de filosofia. É uma obra de maturidade filosófica, fruto do dialogo com acadêmicos em diálogo com a história da filosofia. Abre caminho para o ensino e a aprendizagem da filosofia em todos os níveis acadêmicos.

Com a realização deste estudo teórico, também pudemos concluir que o método de Gallo (2014), em seus quatro passos didáticos para a operacionalização da aula de filosofia, favorece o diálogo filosófico, a interação ensino e aprendizagem, a criação e produção de conceitos filosóficos - elemento essencial do conhecimento filosófico, de um lado, e de outro lado, instrumento para o professor que deseja abrir caminho para filosofar com a história da filosofia, sem dicotomia do ensino de filosofia e do exercício do filosofar. Sendo assim, o professor de filosofia deve colocar-se em atitude de "ignorância" filosófica no sentido socrático, caso contrário, a aula corre o risco de ser transformada em monólogo, atitude ainda em processo de superação.

Além disso, para o estudante colocar em prática o exercício do filosofar, necessita sentir na alma a necessidade do conhecimento filosófico e também ser envolvido em todo o processo 
ensino-aprendizagem, desde a sensibilização até à criação de conceitos. Portanto, a sensibilização, como a primeira das quatro etapas do ensino filosófico, mediada pelo universo cultural que compõe a vida do estudante, o problematizar o tema em pauta, como alma de todo o processo do conhecimento filosófico, a fundamentação teórica tecida pela história da filosofia em cada etapa da história e a produção de conceitos são o caminho para o êxito da aula de filosofia.

A partir desta perspectiva, é preciso ensinar aos estudantes não apenas filosofia, mas também a necessidade da filosofia, bem como de outras ciências para a significação da vida. Todavia, percebemos a problemática de que, no atual contexto do ensino de filosofia no Ensino Médio, os professores, em sua maioria, não possuem formação acadêmica na referida área de conhecimento filosófico e, por isso, uma grande quantidade de alunos situa-se longe da compreensão e linguagem filosóficas, o que, por sua vez, inviabiliza uma aprendizagem prazerosa sobre os conhecimentos filosóficos.

Portanto, merecem atenção dos educadores: Para que queremos o ensino da disciplina de Filosofia no Ensino Médio? É possível ensinar Filosofia ou ensinar a filosofar? Como essa disciplina deve ser ensinada? Como tem sido a formação dos professores de Filosofia? O tempo ofertado para as discussões filosóficas é suficiente para uma reflexão que seja de fato produtiva? Há materiais didáticos para esta finalidade? Esse material é suficiente para a demanda de discussões que devemos promover em sala de aula? Apenas de uma coisa temos certeza: iremos filosofar sempre.

\section{REFERÊNCIAS}

ASPIS, Renata Pereira Lima. O Ensino de Filosofia no Ensino Médio como experiência Filosófica. Cad. Cedes, Campinas, vol. 24, n. 64, p. 305-320, set./dez. 2004

BARBOSA, C. L. A. Didática e filosofia no ensino médio: um diálogo possível. Revista Educação da Unisinos, v.12, n.2, p. 11-19, 2008.

DELEUZE, G; GUATTARI, F. O que é a filosofia? São Paulo: Editora 34, 2010.

FRANÇOIS, Zourabichvili. O vocabulário de Deleuze. Tradução André Telles RJ: Ifchunicamp 2004

GALLO, S. Metodologia do Ensino de Filosofia. Editora: Papirus, 2014.

GASSET, J. O Que é filosofia? Rio de Janeiro: Ibero-Americano, 1971.

GIL, A. C. Como elaborar projeto de pesquisas. $4^{\text {a }}$ Ed. São Paulo: Atlas, 2009.

KANT, I. Crítica da razão pura. 2. ed. São Paulo: Abril Cultural, 1983. (Coleção "Os Pensadores").GONÇALVES, J. C; SILVA, D.J. Filosofo versus Professor de Filosofia: o 
ensino de filosofia e a formação de professores filósofos.Revista Saber Acadêmico da Universidade Estadual de São Paulo - UNIESP, n. 11, p. 80-81, jun. 2011.

OBIOLS, G. Uma introdução ao ensino da filosofia. Ijuí: UNIJUÍ, 2002.

PIZZANI, L; SILVA, R. C; BELLO, S. F; HAUASHI, M. C. P. I. A arte da pesquisa bibliográfica na busca do conhecimento.Revista Digital de Biblioteconomia e Ciência da Informação. Campinas, SP, v. 10, n. 1, p. 53-66, jul./dez. 2012.

RANCIERE, Jacques. O mestre ignorante: Cinco lições sobre a emancipação intelectual. Belo Horizonte: Autêntica.2002.

SANTANA, L. N. Sentido da filosofia no Ensino Médio: contribuições para a formação do jovem na óptica do professor. Dissertação de Mestrado em Educação. Universidade Católica de Santos, Santos, SP, 2007. Disponível em: $<\underline{\text { http://biblioteca.unisantos.br:8181/bitstream/tede/167/1/Luiz } \% 20 \text { Carlos } \% 20 d e \% 20 S a n t a n a . ~}$ pdf $>$ 